\title{
Association of polymorphisms in the telomere-related gene ACYP2 with lung cancer risk in the Chinese Han population
}

\author{
Nanzheng Chen ${ }^{1, *}$, Xiaomei Yang ${ }^{2, *}$, Wen Guo ${ }^{3}$, Jiangtao You ${ }^{1}$, Qifei Wu ${ }^{1}$, Guangjian \\ Zhang ${ }^{1}$, Haijun $\mathrm{Li}^{1}$, Donghong Geng ${ }^{4}$, Tianbo Jin' ${ }^{5}$, Junke Fu' ${ }^{1}$, Yong Zhang ${ }^{1}$ \\ ${ }^{1}$ Department of Thoracic Surgery, The First Affiliated Hospital of Xi'an Jiaotong University, Xi'an 710061, Shaanxi, China \\ ${ }^{2}$ Hospital 521 of China's Ordnance Industry Group, Xi'an 710065, Shaanxi, China \\ ${ }^{3}$ Inner Mongolia Medical University, Hohhot 010050, Inner Mongolia, China \\ ${ }^{4}$ School of Continuing Education of Xi'an Jiaotong University, Xi'an 710061, Shaanxi, China \\ ${ }^{5}$ School of Life Sciences, Northwest University, Xi'an 710069, Shaanxi, China \\ * These authors have contributed equally to this work \\ Correspondence to: Junke Fu, email: aniywn666888@163.com \\ Yong Zhang, email: cj163.cool@163.com
}

Keywords: association study, lung cancer, telomere-related gene, single nucleotide polymorphisms (SNPS)

Received: August 26, 2016

Accepted: October 14, 2016

Published: December 10, 2016

\section{ABSTRACT}

Single nucleotide polymorphisms (SNPs) in the telomere-associated gene ACYP2 are associated with increased lung cancer risk. We explored the correlation between ACYP2 SNPs and lung cancer susceptibility in the Chinese Han population. A total of 554 lung cancer patients and 603 healthy controls were included in this study. Thirteen SNPs in ACYP2 were selected. Odds ratios (ORs) and 95\% confidence intervals ( $95 \%$ CIs) were calculated using unconditional logistic regression analysis. Multivariate logistic regression analysis was used assess the correlation between SNPs and lung cancer. We found that rs1682111 was associated with increased lung cancer risk in the recessive model (crude, $O R=1.50,95 \% C I$ : 1.04-2.16, $p=0.029$; adjusted for age, $O R=1.55,95 \% C I: 1.04-2.30, p=0.029)$, as was rs11896604 in the codominant model (crude, $\mathrm{OR}=0.65,95 \% \mathrm{CI}$ : $0.33-1.28, \mathrm{p}=0.045$; adjusted for age, $\mathrm{OR}=0.74,95 \% \mathrm{CI}: 0.36-1.53, \mathrm{p}=0.049$ ) and over-dominant model (crude, $\mathrm{OR}=1.30$, 95\%CI: 1.02-1.66, $\mathrm{p}=0.032$; adjusted for age, $\mathrm{OR}=1.37,95 \% \mathrm{CI}: 1.05-1.78, \mathrm{p}=0.020$ ). Finally, rs843720 was associated with increased lung cancer risk in the recessive model (crude, $O R=1.43,95 \% C I$ : 1.02-2.02, $p=0.040$; adjusted for age, $O R=1.48$, 95\%CI: 1.02-2.15, $\mathrm{p}=0.040)$. Thus three SNPs in ACYP2 (rs1682111, rs11896604 and rs843720) associate with lung cancer in the Chinese Han population.

\section{INTRODUCTION}

Lung cancer, the leading cause of cancer-related death in most countries, has been increasing rapidly in China for the last three decades [1]. The risk of lung cancer is strongly associated with exposure to environmental carcinogens, in particular to cigarette smoke [2]. However, only approximately $10 \%$ of smokers ever develop lung cancer. This highlights the potential role of hereditary components in determining the risk of lung cancer [3]. Through genome-wide association studies (GWAS), a number of genes involved in lung carcinogenesis have been identified in populations of European descent. These include CHRNA5, CHRNA3 and CHRNA4 on chromosome 15q25.1 [4-6], (TERT-CLPTM1L) on 5p15.33 [7, 8], and (BAT3-MSH5) on 6p21.33 [7].

It was also learned from GWAS that inherited single nucleotide polymorphisms (SNPs) in telomere-related genes are associated with various malignancies [9]. Human telomeres, composed of a tandem hexanucleotide repeat (TTAGGG), are many kilobases long in newborns but shorten by an average of 20-40 base-pairs annually [10]. SNPs in the telomere-related gene $A C Y P 2$ are reproducibly associated with inter-individual variation in leukocyte telomere length (LTL) [11]. In addition, recent Mendelian randomization studies indicate that LTL- 
Table 1: Characteristics of the cases and controls

\begin{tabular}{|c|c|c|c|c|}
\hline Variables & Case $(N=554)$ & Control $(\mathrm{N}=603)$ & Total & $p$ \\
\hline Gender, No. (\%) & & & & $0.282^{\mathrm{a}}$ \\
\hline Male & $416(75.1 \%)$ & $469(77.8 \%)$ & 885 & \\
\hline Female & $138(24.9 \%)$ & $134(22.2 \%)$ & 272 & \\
\hline Mean age \pm SD & $48.24 \pm 13.05$ & $58.18 \pm 10.53$ & & $<0.001^{\mathrm{b}}$ \\
\hline
\end{tabular}

${ }^{a} p$ was calculated using the chi-square test.

${ }^{b} p$ was calculated using Student's t-test.

associated SNPs related to longer telomere lengths are associated with increased risk of adult glioma, melanoma and lung cancer [12].

As far as we know, no studies have investigated the correlations between SNPs in $A C Y P 2$ and lung cancer susceptibility. We therefore performed a case-control association study to determine whether any of 13 SNPs in the $A C Y P 2$ gene are associated with lung cancer susceptibility in the Chinese Han population.

\section{RESULTS}

\section{Participant characteristics}

A total of 554 lung cancer patients (416 males, 138 females; median age at diagnosis $48.24 \pm 13.05$ years) and 603 healthy subjects (469 males, 134 females; median age $58.18 \pm 10.53$ years) were enrolled in our study. There is significant difference in age between patients in the case and control groups $(p<0.001)$, but no difference in gender (Table 1).

\section{Association between $A C Y P 2$ polymorphisms and lung cancer risk}

The minor allele of each SNP was assumed to be a risk factor. The minor allele frequencies (MAF) are listed in Table 2. As a risk factor, the minor allele of each SNP was compared with the wild-type allele. All of the tested SNPs were consistent with the Hardy-Weinberg equilibrium for the control population of this study $(p>0.05)$. Comparing the differences in the frequency distributions of the alleles between the cases and controls using the $\chi^{2}$ test, we found no correlation between the loci and lung cancer susceptibility.

After adjusting for age, the models were further analyzed using unconditional logistic regression analysis of SNPs associated with lung cancer (Table 3). We found that the AA genotype of rs1682111 was associated with increased lung cancer risk under the recessive model (crude, $\mathrm{OR}=1.50,95 \% \mathrm{CI}$ : 1.04-2.16, $p=0.029$; adjusted for age, $\mathrm{OR}=1.55,95 \% \mathrm{CI}$ : 1.04-2.30, $p=0.029)$. We also noticed that rs 11896604 was associated with lung cancer risk in codominant model ("GG", crude, $\mathrm{OR}=0.65$, 95\% CI: $0.33-1.28, p=0.045$; adjusted for age, $\mathrm{OR}=0.74$, 95\%CI: $0.36-1.53, p=0.049)$ and over-dominant model ("CG", crude, OR=1.30, 95\%CI: 1.02-1.66, $p=0.032$; adjusted for age, $\mathrm{OR}=1.37,95 \% \mathrm{CI}: 1.05-1.78, p=0.020)$. In addition, the GG genotype of rs843720 increased the risk of lung cancer under the recessive model (crude, $\mathrm{OR}=1.43,95 \% \mathrm{CI}: 1.02-2.02, p=0.040$; adjusted for age, $\mathrm{OR}=1.48,95 \% \mathrm{CI}: 1.02-2.15, \mathrm{p}=0.040)$.

Finally, we also performed a Wald test using unconditional multivariate regression analysis to assess the associations between SNP haplotypes and lung cancer risk. However, no positive results were observed.

\section{DISCUSSION}

In this study, three SNPs (rs1682111, rs11896604 and rs843720) were found to be associated with the lung cancer susceptibility in the Chinese Han population. Rs1682111 was associated with increased lung cancer risk in the recessive model. An association between this locus and other diseases has not been previously reported. Although this is the first report that rs 11896604 associates with lung cancer susceptibility in the codominant overdominant model, it was previously suggested that rs11896604 associates with a decreased risk of breast cancer [13]. In addition, rs843720 associated with an increased the risk of lung cancer in the recessive model.

$A C Y P 2$, located on chromosome 2p16.2, encodes a small cytosolic enzyme acylphosphatase that catalyzes the dephosphorylation of phospho-enzyme intermediates of various membrane pumps, particularly the $\mathrm{Ca}^{2+} / \mathrm{Mg}^{2+}$ ATPase from sarcoplasmic reticulum of skeletal muscle [14]. The physiological function of $A C Y P 2$ is not yet completely clear, however. Vos et al. reported that the rs1872328 variant of $A C Y P 2$ was associated with cisplatininduced ototoxicity in patients with osteosarcoma who did not receive potentially ototoxic cranial irradiation [15]. It was further suggested that severe oxaliplatin-induced chronic peripheral neurotoxicity was potentially associated with $A C Y P 2$ rs843748 [16]. A recent genome-wide metaanalysis showed that $A C Y P 2$ rs11125529 affects telomere length and coronary heart disease in the Chinese Han 
Table 2: Basic information on the candidate SNPs

\begin{tabular}{|c|c|c|c|c|c|c|c|c|}
\hline \multirow{2}{*}{ Rs number } & \multirow{2}{*}{$\begin{array}{c}\text { Nucleotide } \\
\text { position }\end{array}$} & \multirow{2}{*}{$\begin{array}{c}\text { Allele } \\
\text { A/B }\end{array}$} & \multicolumn{2}{|c|}{ MAF frequency } & \multirow{2}{*}{$\begin{array}{c}\text { HW } \\
p\end{array}$} & \multicolumn{2}{|c|}{ Allele model } & \multirow{2}{*}{$p$} \\
\hline & & & case & control & & OR & $95 \% \mathrm{CI}$ & \\
\hline rs6713088 & 54345469 & $\mathrm{G} / \mathrm{C}$ & 0.404 & 0.393 & 0.089 & 1.048 & $0.887-1.237$ & 0.585 \\
\hline rs 12621038 & 54391113 & $\mathrm{~T} / \mathrm{C}$ & 0.454 & 0.465 & 0.368 & 0.956 & $0.812-1.126$ & 0.591 \\
\hline rs1682111 & 54427979 & $\mathrm{~A} / \mathrm{T}$ & 0.347 & 0.309 & 0.924 & 1.189 & $1.000-1.415$ & 0.051 \\
\hline rs843752 & 54446587 & $\mathrm{G} / \mathrm{T}$ & 0.234 & 0.260 & 0.089 & 0.870 & $0.720-1.052$ & 0.151 \\
\hline rs10439478 & 54459450 & $\mathrm{C} / \mathrm{A}$ & 0.430 & 0.433 & 0.245 & 0.987 & $0.837-1.164$ & 0.880 \\
\hline rs843645 & 54474664 & $\mathrm{G} / \mathrm{T}$ & 0.225 & 0.250 & 0.065 & 0.874 & $0.721-1.059$ & 0.169 \\
\hline rs11125529 & 54475866 & $\mathrm{~A} / \mathrm{C}$ & 0.195 & 0.187 & 0.503 & 1.054 & $0.857-1.298$ & 0.617 \\
\hline rs12615793 & 54475914 & $\mathrm{~A} / \mathrm{G}$ & 0.211 & 0.200 & 0.702 & 1.072 & $0.876-1.312$ & 0.499 \\
\hline rs843711 & 54479117 & $\mathrm{~T} / \mathrm{C}$ & 0.436 & 0.448 & 0.510 & 0.953 & $0.809-1.123$ & 0.567 \\
\hline rs11896604 & 54479199 & $\mathrm{G} / \mathrm{C}$ & 0.214 & 0.200 & 0.800 & 1.087 & $0.889-1.330$ & 0.415 \\
\hline rs843706 & 54480369 & $\mathrm{~A} / \mathrm{C}$ & 0.432 & 0.452 & 0.459 & 0.925 & $0.784-1.091$ & 0.355 \\
\hline rs 17045754 & 54496757 & $\mathrm{C} / \mathrm{G}$ & 0.196 & 0.187 & 1.000 & 1.062 & $0.863-1.307$ & 0.570 \\
\hline rs843720 & 54510660 & $\mathrm{G} / \mathrm{T}$ & 0.380 & 0.343 & 0.527 & 1.171 & $0.988-1.388$ & 0.068 \\
\hline
\end{tabular}

SNPs: Single nucleotide polymorphisms; MAF: Minor allele frequency; HWE: Hardy-Weinberg equilibrium; OR: Odds ratio; CI: Confidence interval; A: Minor alleles; B: Major alleles.

population [17]. In addition, Yongjun et al found that ACYP2 rs12615793 and rs11896604 may significantly decrease the risk of high-altitude pulmonary edema [18]. However, the mechanism by which $A C Y P 2$ contributes to lung cancer will need to be explored in future studies.

Although the present study has several strengths, it also has intrinsic limitations. First, we present no data on the relation between $A C Y P 2$ SNPs and the most influential lung cancer risk: smoking. Second, the size of our sample is relatively small. Finally, other factors such as BMI, bacterial and viral infection, marriage, and economic status were not taken into account. Those issues will be addressed in future studies, along with further characterization of the molecular mechanism underlying the association of $A C Y P 2$ SNPs and lung cancer and prospective studies to validate their clinical utility.

In sum, we have identified several novel associations between three SNPs in ACYP2 (rs1682111, rs11896604 and rs843720) and lung cancer in the Chinese Han population. Our findings suggest $A C Y P 2$ may be a useful marker that informs clinical decisions, and may shed light on new candidate genes and new ideas about the mechanism governing the occurrence of lung cancer.

\section{MATERIALS AND METHODS}

\section{Study participants}

We recruited 554 patients with lung cancer and 603 healthy controls for this study. The patients were treated at the First Affiliated Hospital of Xi'an Jiao Tong University between January 2014 and August 2016. All demographic and related clinical data, including residential region, age, ethnicity, and education status, were collected through a face-to-face questionnaire and review of medical records. Patients recently diagnosed with primary lung cancer (confirmed by histopathological analysis) were included. Patients with other types of cancers or who underwent radiotherapy or chemotherapy were excluded. The controls underwent annual health evaluations in the checkup centers affiliated with our institution. All control patients were in good health and had no history of cancer, and they had no blood relatives with lung cancer going back three generations. This research was performed in accordance with the Chinese Department of Health and Human Services regulations for the protection of human research subjects. We obtained informed consent from all of the participants, and the study protocols were approved by the Institutional Review Board of Xi'an Jiao Tong University.

\section{SNP selection and genotyping}

Thirteen SNPs in $A C Y P 2$ that had a MAF $>5 \%$ in the HapMap Asian population were selected for the association analysis $[13,14]$. Venous blood samples $(5 \mathrm{~mL})$ were collected from each study participant during a laboratory examination. Blood samples from patients were collected prior to radiation or chemotherapy. DNA was extracted from whole blood samples using a Gold Mag-Mini Whole 
Table 3: Single loci associated with lung cancer (adjusted by age)

\begin{tabular}{|c|c|c|c|c|c|c|c|c|}
\hline \multirow{2}{*}{ SNPs } & \multirow{2}{*}{ Model } & \multirow{2}{*}{ Genotype } & \multirow{2}{*}{ Controls(n\%) } & \multirow{2}{*}{ Cases(n\%) } & \multicolumn{2}{|c|}{ Without adjustment } & \multicolumn{2}{|c|}{ With adjustment } \\
\hline & & & & & OR $(95 \%$ CI $)$ & $p 1$ & OR $(95 \% \mathrm{CI})$ & $p^{2}$ \\
\hline \multirow[t]{10}{*}{ rs1682111 } & Codominant & $\mathrm{T} / \mathrm{T}$ & $287(47.6 \%)$ & $244(44.0 \%)$ & $1[\mathrm{Ref}]$ & & $1[\mathrm{Ref}]$ & \\
\hline & & $\mathrm{T} / \mathrm{A}$ & $259(43 \%)$ & $235(42.4 \%)$ & $1.07(0.83-1.36)$ & & $1.01(0.78-1$ & \\
\hline & & $\mathrm{A} / \mathrm{A}$ & $57(9.4 \%)$ & $75(13.5 \%)$ & $1.55(1.05-2.27)$ & 0.080 & $1.56(1.03-2.37)$ & 0.092 \\
\hline & Dominant & $\mathrm{T} / \mathrm{T}$ & $287(47.6 \%)$ & $244(44.0 \%)$ & $1[\operatorname{Ref}]$ & & $1[\operatorname{Ref}]$ & \\
\hline & & $\mathrm{T} / \mathrm{A}-\mathrm{A} / \mathrm{A}$ & $316(52.4 \%)$ & $310(56.0 \%)$ & $1.15(0.9-21.45)$ & 0.230 & $1.11(0.86-1.43)$ & 0.420 \\
\hline & Recessive & $\mathrm{T} / \mathrm{T}-\mathrm{T} / \mathrm{A}$ & $546(90.5 \%)$ & $479(86.5 \%)$ & $1[\operatorname{Ref}]$ & & $1[\mathrm{Ref}]$ & \\
\hline & & $\mathrm{A} / \mathrm{A}$ & $57(9.4 \%)$ & $75(13.5 \%)$ & $1.50(1.04-2.16)$ & 0.029 & $1.55(1.04-2.30)$ & 0.029 \\
\hline & $\begin{array}{c}\text { Over- } \\
\text { dominant }\end{array}$ & T/T-A/A & $344(57 \%)$ & $319(57.6 \%)$ & $1[\operatorname{Ref}]$ & & $1[\operatorname{Ref}]$ & \\
\hline & & $\mathrm{T} / \mathrm{A}$ & $259(43 \%)$ & $235(42.4 \%)$ & $0.98(0.77-1.24)$ & 0.850 & $0.93(0.72-1.19)$ & 0.550 \\
\hline & Log-additive & - & - & - & $1.18(1.00-1.40)$ & 0.054 & $1.17(0.97-1.41)$ & 0.100 \\
\hline \multirow[t]{10}{*}{ rs11896604 } & Codominant & $\mathrm{C} / \mathrm{C}$ & $386(64.1 \%)$ & $331(59.8 \%)$ & $1[\operatorname{Ref}]$ & & $1[\operatorname{Ref}]$ & \\
\hline & & $\mathrm{C} / \mathrm{G}$ & $191(31.7 \%)$ & $209(37.7 \%)$ & $1.28(1.00-1.63)$ & & $1.35(1.03-1$ & \\
\hline & & $\mathrm{G} / \mathrm{G}$ & $25(4.2 \%)$ & $14(2.50 \%)$ & $0.65(0.33-1.28)$ & 0.045 & $0.74(0.36-1.53)$ & 0.049 \\
\hline & Dominant & $\mathrm{C} / \mathrm{C}$ & $386(64.1 \%)$ & $331(59.8 \%)$ & $1[\mathrm{Ref}]$ & & $1[\operatorname{Ref}]$ & \\
\hline & & $\mathrm{C} / \mathrm{G}-\mathrm{G} / \mathrm{G}$ & $216(35.9 \%)$ & $223(40.2 \%)$ & $1.20(0.95-1.53)$ & 0.130 & $1.28(0.99-1.66)$ & 0.062 \\
\hline & Recessive & $\mathrm{C} / \mathrm{C}-\mathrm{C} / \mathrm{G}$ & $577(95.8 \%)$ & $540(97.5 \%)$ & $1[\mathrm{Ref}]$ & & $1[\mathrm{Ref}]$ & \\
\hline & & $\mathrm{G} / \mathrm{G}$ & $25(4.2 \%)$ & $14(2.50 \%)$ & $0.60(0.31-1.16)$ & 0.120 & $0.66(0.32-1.37)$ & 0.260 \\
\hline & $\begin{array}{c}\text { Over- } \\
\text { dominant }\end{array}$ & $\mathrm{C} / \mathrm{C}-\mathrm{G} / \mathrm{G}$ & $411(68.3 \%)$ & $345(62.3 \%)$ & $1[\mathrm{Ref}]$ & & $1[\mathrm{Ref}]$ & \\
\hline & & $\mathrm{C} / \mathrm{G}$ & $191(31.7 \%)$ & $209(37.7 \%)$ & $1.30(1.02-1.66)$ & 0.032 & $1.37(1.05-1.78)$ & 0.020 \\
\hline & Log-additive & - & - & - & $1.09(0.89-1.34)$ & 0.400 & $1.16(0.92-1.45)$ & 0.200 \\
\hline \multirow[t]{10}{*}{ rs 843720} & Codominant & $\mathrm{T} / \mathrm{T}$ & $256(42.5 \%)$ & $217(39.2 \%)$ & $1[\operatorname{Ref}]$ & & $1[\operatorname{Ref}]$ & \\
\hline & & $\mathrm{G} / \mathrm{T}$ & $280(46.4 \%)$ & $252(45.6 \%)$ & $1.06(0.83-1.36)$ & & $1.07(0.82-1$ & \\
\hline & & $\mathrm{G} / \mathrm{G}$ & $67(11.1 \%)$ & $84(15.2 \%)$ & $1.48(1.02-2.14)$ & 0.110 & $1.54(1.03-2.29)$ & 0.110 \\
\hline & Dominant & $\mathrm{T} / \mathrm{T}$ & $256(42.5 \%)$ & $217(39.2 \%)$ & $1[\mathrm{Ref}]$ & & $1[\operatorname{Ref}]$ & \\
\hline & & G/T-G/G & $347(57.5 \%)$ & $336(60.8 \%)$ & $1.14(0.90-1.44)$ & 0.270 & $1.16(0.90-1.50)$ & 0.250 \\
\hline & Recessive & $\mathrm{T} / \mathrm{T}-\mathrm{G} / \mathrm{T}$ & $536(88.9 \%)$ & $469(84.8 \%)$ & $1[\operatorname{Ref}]$ & & $1[\operatorname{Ref}]$ & \\
\hline & & $\mathrm{G} / \mathrm{G}$ & $67(11.1 \%)$ & $84(15.2 \%)$ & $1.43(1.02-2.02)$ & 0.040 & $1.48(1.02-2.15)$ & 0.040 \\
\hline & $\begin{array}{c}\text { Over- } \\
\text { dominant }\end{array}$ & $\mathrm{T} / \mathrm{T}-\mathrm{G} / \mathrm{G}$ & $323(53.6 \%)$ & $301(54.4 \%)$ & $1[\operatorname{Ref}]$ & & $1[\operatorname{Ref}]$ & \\
\hline & & $\mathrm{G} / \mathrm{T}$ & $280(46.4 \%)$ & $252(45.6 \%)$ & $0.97(0.77-1.22)$ & 0.770 & $0.97(0.75-1.25)$ & 0.810 \\
\hline & Log-additive & - & - & - & $1.17(0.99-1.39)$ & 0.068 & $1.19(0.99-1.43)$ & 0.064 \\
\hline
\end{tabular}

SNPs: Single nucleotide polymorphisms; OR: Odds ratio. CI: Confidence interval.

Values of $p$ were calculated using the Wald test; $p<0.05$ was considered significant.

Blood Genomic DNA Purification Kit (GoldMag Ltd, Xian, China) and stored at $-80^{\circ} \mathrm{C}$ after centrifugation. The DNA concentration was measured using spectrometry (DU530 UV/VIS spectrophotometer, Beckman Instruments, Fullerton, CA, USA). Sequenom MassARRAY Assay
Design 3.0 software (Sequenom, Inc, San Diego, CA, USA) was used to design the multiplexed SNP Mass EXTEND assay, and genotyping was performed using a Sequenom MassARRAY RS1000 (Sequenom, Inc.) according to the manufacturer's protocol. SequenomTyper 4.0 Software ${ }^{\mathrm{TM}}$ 
Table 4: Primers used

\begin{tabular}{|c|c|c|c|}
\hline SNP_ID & 1st-PCRP & 2nd-PCRP & UEP_SEQ \\
\hline rs6713088 & ACGTTGGATGACACACACAGACTCCTTCAC & ACGTTGGATGGTCACCAAAACACGTAATG & gaggcCAGAATGGTCCACTAGAGA \\
\hline rs 12621038 & ACGTTGGATGATTGTGCTAGGCACTTTAGG & ACGTTGGATGGGCATAAGTTTTATTGCCTC & ccATTGCCTCAGCTAGACT \\
\hline rs1682111 & ACGTTGGATGGAATTGCTGGGTTATTTGGC & ACGTTGGATGGCCAGTGGGAATGCAAAATG & tgtcATGCAAAATGAAACAGACACTT \\
\hline rs843752 & ACGTTGGATGTCCTCTTTTCAGAAACCTGC & ACGTTGGATGGAGACAACATAATGGAGGTC & cGAGTTTGGGTTTGAGGT \\
\hline rs 10439478 & ACGTTGGATGTAGCACAAGACCTACACTGG & ACGTTGGATGCTACACTCTCCAGAGGAATG & TTGCTGTTTTCCCAGAA \\
\hline rs843645 & ACGTTGGATGGAAATCTGAATACCACCTAC & ACGTTGGATGACAGTGCCTTTAGCAAGGTG & TCATAGGCACTACTGTATC \\
\hline rs11125529 & ACGTTGGATGCCGAAGAAAAGAAGATGAC & ACGTTGGATGGAGCTTAGTTGTTTACAGATG & AGAAAAGAAGATGACTAAAACAT \\
\hline rs 12615793 & ACGTTGGATGATCTTGGCCCTTGAAGAA & ACGTTGGATGTTTGAGCTTAGTTGTTTAC & AAATTGAGTGACAAATATAAACTAC \\
\hline rs843711 & ACGTTGGATGGACAAAGGACCTTACAACTC & ACGTTGGATGTGCCTTGTGGGAATTAGAGC & gggaTCAGGGAACCAGTGCAAA \\
\hline rs11896604 & ACGTTGGATGAAGTCAGAATAGTGCTTAC & ACGTTGGATGTGTCTCTGACCTAGCATGTA & GTTAAGCTTGCAAGGAG \\
\hline rs843706 & ACGTTGGATGTGAAAGCCATAAATATTTTG & ACGTTGGATGTGAATAACTTGGTCTTATC & cACTTGGTCTTATCTGATGC \\
\hline rs17045754 & ACGTTGGATGCTGTAAAAGTTCTGGCATGG & ACGTTGGATGGAAATCAGGGATATTAGTGC & caggTATTCAGCTTCCTAGAGTTA \\
\hline rs843720 & ACGTTGGATGCTTCACAACACTCCTGTAAG & ACGTTGGATGAGTCAGAGCTAGACCTCTGG & cсcсAATCTGTCTCAGGGTCTT \\
\hline
\end{tabular}

(Sequenom, Inc.) was used to manage and analyze the data. The primers corresponding to each SNP are shown in Table 4. Based on these results, the following 13 SNPs were selected: rs6713088, rs12621038, rs1682111, rs843752, rs10439478, rs843645, rs11125529, rs12615793, rs843711, rs11896604, rs843706, rs17045754 and rs843720. Basic information on the SNPs is shown in Table 2.

\section{Statistical analysis}

We used Chi-squared tests (categorical variables) and Student's t-tests (continuous variables) to assess the differences in the demographic characteristics between the cases and controls. The Hardy-Weinberg equilibrium of each SNP was assessed in order to compare the expected frequencies of the genotypes in the control groups. All minor alleles were regarded as risk alleles for lung cancer susceptibility. To evaluate associations between each SNP and lung cancer risk in the five models (codominant, dominant, recessive, over-dominant and log-additive), ORs and 95\% CIs were calculated using unconditional logistic regression analysis after adjusting for age, and gender. Linkage disequilibrium analysis and SNP haplotypes were analyzed using the Haploview software package (version 4.2) and the SHEsi software platform (http://www.nhgg.org/analysis/). All statistical analyses were performed using the SPSS version 17.0 statistical package (SPSS, Chicago, IL, USA) and Microsoft Excel. All statistical tests were two-sided, and values of $p<0.05$ was considered significant.

\section{ACKNOWLEDGMENTS}

This work was supported by the Fundamental Research Funds for the Central University of China [No.08143004] and the Funds for Science and
Technology Project of Shaanxi Province of China [No.2014K11-02-03-07]. The authors are also grateful to the patients and control individuals for their participation in the study. We thank the clinicians and hospital staff who contributed to sample and data collection for this study.

\section{CONFLICTS OF INTEREST}

The authors declare no conflicts of interest.

\section{REFERENCES}

1. Hu Z, Wu C, Shi Y, Guo H, Zhao X, Yin Z, Yang L, Dai J, Hu L, Tan W, Li Z, Deng Q, Wang J, Wu W, Jin G, Jiang Y, et al. A genome-wide association study identifies two new lung cancer susceptibility loci at $13 \mathrm{q} 12.12$ and $22 \mathrm{q} 12.2$ in Han Chinese. Nature genetics. 2011; 43:792-796.

2. Chaturvedi AK, Caporaso NE, Katki HA, Wong HL, Chatterjee N, Pine SR, Chanock SJ, Goedert JJ, Engels EA. C-reactive protein and risk of lung cancer. Journal of clinical oncology: official journal of the American Society of Clinical Oncology. 2010; 28:2719-2726.

3. Spinola M, Meyer P, Kammerer S, Falvella FS, Boettger MB, Hoyal CR, Pignatiello C, Fischer R, Roth RB, Pastorino U, Haeussinger K, Nelson MR, Dierkesmann R, Dragani TA, Braun A. Association of the PDCD5 locus with lung cancer risk and prognosis in smokers. Journal of clinical oncology: official journal of the American Society of Clinical Oncology. 2006; 24:1672-1678.

4. Hung RJ, McKay JD, Gaborieau V, Boffetta P, Hashibe M, Zaridze D, Mukeria A, Szeszenia-Dabrowska N, Lissowska J, Rudnai P, Fabianova E, Mates D, Bencko V, Foretova L, Janout V, Chen C, et al. A susceptibility locus for lung cancer maps to nicotinic acetylcholine receptor subunit genes on 15q25. Nature. 2008; 452:633-637. 
5. Amos CI, Wu X, Broderick P, Gorlov IP, Gu J, Eisen T, Dong Q, Zhang Q, Gu X, Vijayakrishnan J, Sullivan K, Matakidou A, Wang Y, Mills G, Doheny K, Tsai YY, et al. Genome-wide association scan of tag SNPs identifies a susceptibility locus for lung cancer at $15 \mathrm{q} 25.1$. Nature genetics. 2008; 40:616-622.

6. Thorgeirsson TE, Geller F, Sulem P, Rafnar T, Wiste A, Magnusson KP, Manolescu A, Thorleifsson G, Stefansson H, Ingason A, Stacey SN, Bergthorsson JT, Thorlacius S, Gudmundsson J, Jonsson T, Jakobsdottir M, et al. A variant associated with nicotine dependence, lung cancer and peripheral arterial disease. Nature. 2008; 452:638-642.

7. Wang Y, Broderick P, Webb E, Wu X, Vijayakrishnan J, Matakidou A, Qureshi M, Dong Q, Gu X, Chen WV, Spitz MR, Eisen T, Amos CI, Houlston RS. Common 5p15.33 and $6 \mathrm{p} 21.33$ variants influence lung cancer risk. Nature genetics. 2008; 40:1407-1409.

8. McKay JD, Hung RJ, Gaborieau V, Boffetta P, Chabrier A, Byrnes G, Zaridze D, Mukeria A, Szeszenia-Dabrowska N, Lissowska J, Rudnai P, Fabianova E, Mates D, Bencko V, Foretova L, Janout V, et al. Lung cancer susceptibility locus at 5p15.33. Nature genetics. 2008; 40:1404-1406.

9. Walsh KM, Whitehead TP, de Smith AJ, Smirnov IV, Park M, Endicott AA, Francis SS, Codd V, Group ECT, Samani NJ, Metayer C, Wiemels JL. Common genetic variants associated with telomere length confer risk for neuroblastoma and other childhood cancers. Carcinogenesis. 2016; 37:576-582.

10. Daniali L, Benetos A, Susser E, Kark JD, Labat C, Kimura M, Desai K, Granick M, Aviv A. Telomeres shorten at equivalent rates in somatic tissues of adults. Nature communications. 2013; 4:1597.

11. Codd V, Nelson CP, Albrecht E, Mangino M, Deelen J, Buxton JL, Hottenga JJ, Fischer K, Esko T, Surakka I, Broer L, Nyholt DR, Mateo Leach I, Salo P, Hagg S, Matthews $\mathrm{MK}$, et al. Identification of seven loci affecting mean telomere length and their association with disease. Nature genetics. 2013; 45:422-427, 427e421-422.
12. Zhang C, Doherty JA, Burgess S, Hung RJ, Lindstrom S, Kraft P, Gong J, Amos CI, Sellers TA, Monteiro AN, Chenevix-Trench G, Bickeboller H, Risch A, Brennan P, McKay JD, Houlston RS, et al. Genetic determinants of telomere length and risk of common cancers: a Mendelian randomization study. Human molecular genetics. 2015; 24:5356-5366

13. Liu M, Li B, Guo W, Zhang X, Chen Z, Li J, Yan M, Chen C, Jin T. Association between single nucleotide polymorphisms in the TSPYL6 gene and breast cancer susceptibility in the Han Chinese population. Oncotarget. 2016; 7:54771-54781. doi: 10.18632/oncotarget.10754.

14. Degl'Innocenti D, Marzocchini R, Rosati F, Cellini E, Raugei G, Ramponi G. Acylphosphatase expression during macrophage differentiation and activation of U-937 cell line. Biochimie. 1999; 81:1031-1035.

15. Vos HI, Guchelaar HJ, Gelderblom H, de Bont ES, Kremer LC, Naber AM, Hakobjan MH, van der Graaf WT, Coenen MJ, te Loo DM. Replication of a genetic variant in ACYP2 associated with cisplatin-induced hearing loss in patients with osteosarcoma. Pharmacogenetics and genomics. 2016; 26:243-247.

16. Oguri T, Mitsuma A, Inada-Inoue M, Morita S, Shibata T, Shimokata T, Sugishita M, Nakayama G, Uehara K, Hasegawa Y, Ando Y. Genetic polymorphisms associated with oxaliplatin-induced peripheral neurotoxicity in Japanese patients with colorectal cancer. International journal of clinical pharmacology and therapeutics. 2013; $51: 475-481$.

17. Mathieson I, McVean G. Differential confounding of rare and common variants in spatially structured populations. Nature genetics. 2012; 44:243-246.

18. He Y, Chen J, Zhang X, Li X, Du J, He X, Zhang Z, Zhang Y, Kang L, Jin T, Yuan D. Telomere length related gene ACYP2 polymorphism is associated with the risk of HAPE in Chinese Han population. The journal of gene medicine. 2016. 